\title{
Examination of ceramic restoration adhesive coverage in cusp-replacement premolar using acoustic emission under fatigue testing
}

\author{
Yen-Hsiang Chang ${ }^{1}$, Jin-Jie Yu ${ }^{2}$ and Chun-Li Lin ${ }^{2 *}$
}

\author{
* Correspondence: cllin2@ym.edu.tw \\ ${ }^{2}$ Department of Biomedical \\ Engineering, National Yang-Ming \\ University, No.155, Sec.2, Linong \\ Street, Taipei 112, Taiwan \\ Full list of author information is \\ available at the end of the article
}

\begin{abstract}
Background: This study investigates CAD/CAM ceramic cusp-replacing restoration resistance with and without buccal cusp replacement under static and dynamic cyclic loads, monitored using the acoustic emission (AE) technique.

Method: The cavity was designed in a typical MODP (mesial-occlusal-distal-palatal) restoration failure shape when the palatal cusp has been lost. Two ceramic restorations [without coverage (WOC) and with (WC) buccal cuspal coverage with $2.0 \mathrm{~mm}$ reduction in cuspal height] were prepared to perform the fracture and fatigue tests with normal (200 N) and high (600 N) occlusal forces. The load versus AE signals in the fracture and fatigue tests were recorded to evaluate the restored tooth failure resistance.
\end{abstract}

Results: The results showed that non-significant differences in load value in the fracture test and the accumulated number of AE signals under normal occlusal force $(200 \mathrm{~N})$ in the fatigue test were found between with and without buccal cuspal coverage restorations. The first AE activity occurring for the WOC restoration was lower than that for the WC restoration in the fracture test. The number of AE signals increased with the cyclic load number. The accumulated number of AE signals for the WOC restoration was 187, higher than that (85) for the WC restoration under $600 \mathrm{~N}$ in the fatigue test.

Conclusion: The AE technique and fatigue tests employed in this study were used as an assessment tool to evaluate the resistances in large CAD/CAM ceramic restorations. Non-significant differences in the tested fracture loads and accumulated number of AE signals under normal occlusal force $(200 \mathrm{~N})$ between different restorations indicated that aggressive treatment (with coverage preparation) in palatal cusp-replacing ceramic premolars require more attention for preserving and protecting the remaining tooth.

Keywords: Cuspal-coverage, Ceramic, Acoustic emission, Fatigue, CAD/CAM

\section{Introduction}

With the advances in adhesive methods and ceramic materials, esthetic, metal-free restorations have led to the development of computer design/manufacturing (CAD/CAM) systems for fabricating ceramic inlays, onlays and veneers. CAD/CAM system generated ceramics are currently available that provide a novel means of restoring large cavities in posterior teeth, achieving chair-side design and automated production of all-ceramic monolithic single-unit restorations [1,2]. While the success of any CAD/CAM restoration is multi-factorial, preparation design and marginal adaptation are vital for successful large

(c) 2014 Chang et al.; licensee BioMed Central Ltd. This is an Open Access article distributed under the terms of the Creative Commons Attribution License (http://creativecommons.org/licenses/by/4.0), which permits unrestricted use, distribution, and reproduction in any medium, provided the original work is properly credited. The Creative Commons Public Domain Dedication waiver (http://creativecommons.org/publicdomain/zero/1.0/) applies to the data made available in this article, unless otherwise stated. 
replacements [3-8]. Cavity design becomes more complicated and more difficult to manage when preparing for the onlay restoration. The balance between minimizing the risk of tooth fracture and maximizing the repaired tooth function must be carefully engineered. [9-12].

Structural loss with complete cusp fracture in a posterior tooth accompanied by a failed Class II MOD (mesial-occlusal-distal) restoration is a common phenomenon in dental practice $[9,13,14]$. When a bonded cusp-replacing adhesive restoration depends only on an adhesive system without any accessory retention or resistance in the cavity preparation, the retention strength is often doubtful, as the restored tooth undergoes repeated loads in the oral environment [15]. Kuijs et al. stated that an additional cervical shoulder preparation does not improve the fracture strength of cusp-replacing direct resin composite restorations as long as some retentive form is present [16]. Fennis et al. reported that palatal cuspal coverage increased the fatigue resistance of a direct resin composite restoration [10]. However, these two studies focused only on resin composite restorations and not on CAD/CAM ceramic materials. Chang et al. used FEA and indicated that buccal cusp reduction of at least $1.5 \mathrm{~mm}$ presented more favorable biomechanical performance when cuspal-coverage treatment is considered [3]. Unfortunately, the result of this static numerical study requires further evaluation using insight into the in-vitro fatigue tests to provide more realistic consultation.

The acoustic emission (AE) technique is a non-destructive technique using a sound wave produced by energy released from an externally stimulated material [17]. Locations with flaws under load develop high stress energies and some of this energy is released in the form of a pressure wave or sound that occurs long before the specimen fails catastrophically. This technique can be used to detect the onset and failure progression in structures [17-19]. Combined with conventional static fracture test machines, AE can identify failure initiation, the initial damage site, damage propagation and catastrophic failure of the material and help elucidate the complex failure mechanism [17,20-26]. However, the $\mathrm{AE}$ technique has rarely been employed in dental ceramic fracture testing under cyclic loads. Our previous study successfully combined the AE technique with fatigue shear testing to investigate micro-crack growth and damage in ceramic/dentin adhesive interfaces. The result found that the cumulative number of $\mathrm{AE}$ hits increased with a lower load level in cyclic load tests before fracture [27].

Accordingly, this study applied the $\mathrm{AE}$ technique to monitor the resistance in $\mathrm{CAD} / \mathrm{CAM}$ ceramic restorations with and without buccal cusp replacement under static and dynamic cyclic loads. AE signal results at different cyclic load stages were obtained to understand the biomechanical response of premolar ceramic cuspal-replacing restorations.

\section{Materials and methods} Sample preparation

Eighteen freshly extracted intact maxillary second premolars were stripped of ligaments and stored at $18^{\circ} \mathrm{C}$ in normal saline and randomly assigned to two groups of 9 teeth each. Teeth with similar size and shape were selected using root length and crown dimensions after measuring the buccolingual and mesiodistal widths at the cement-enamel junction (CEJ) in millimeters, allowing for a maximum deviation of $20 \%$ from the mean. All teeth were embedded from the root to 1-mm below the CEJ into an epoxy resin block. 
The cavity was designed in a typical MODP (mesial-occlusal-distal- palatal); i.e., loss of a functional cusp with a 45-degree bevel surface at the cervical margin. The pulpal wall was designed at half the distance between the buccal cusp tip and the CEJ (H), and the isthmus width was two-thirds of the intercuspal width (W) (Figure 1a and b). Two cavity types with 9 teeth in each group were prepared with palatal cusp-replacing ceramic restorations without (WOC) and with (WC) buccal cuspal coverage (Figure 1b and c). The cavity preparation with buccal cuspal coverage was reduced in cuspal height by $2.0 \mathrm{~mm}$ (Figure 1c). The specimen teeth preparation all according to follow steps: Shofu 311 cylinder diamond bur was used to prepare a typical MOD cavity (also used for preparing groups with loss of the buccal cusps teeth) and 45 degree bevel surface was prepared along MOD cavity palatal axiopulpal line angle (simulate a palatal cusp loss on a premolar) by Shofu 211 cylinder diamond bur.

Both the WOC and WC onlay ceramic restorations were designed using the CEREC 3D CAD/CAM unit (Version 3, BlueCam, Sirona, Bensheim, Germany) and machined from ProCAD Lucite-reinforced ceramic blocks (200, I14; Ivoclar Vivadent). Before insertion, the bonding surfaces of the ceramic onlays were etched with hydrofluoric acid (Ultradent Porcelain Etch, 6\%; Ultradent Products, South Jordan, UT, USA) for $90 \mathrm{sec}-$ onds, then dried for 30 seconds in oil-free air. A silane-coupling agent (Monobond S; Ivoclar Vivadent) was applied and allowed to dry for 1 minute. An etch-and-rinse Variolink II adhesive system was applied to bond the tooth structure and ceramic. The exposed tooth structure was acid etched with 35\% phosphoric acid gel $15 \mathrm{sec}$ and air-dried. Heliobond was uniformly applied to the tooth surface. Onlays were seated with light finger pressure and excess luting material was removed. A light-polymerizing unit (Bluephase G2, Ivoclar Vivadent, Liechtenstein) was held on the buccal, mesial, lingual, distal and occlusal surfaces for 40 seconds to 1 minute for each surface. The curing power was $1200 \mathrm{~mW} / \mathrm{cm}^{2}$.

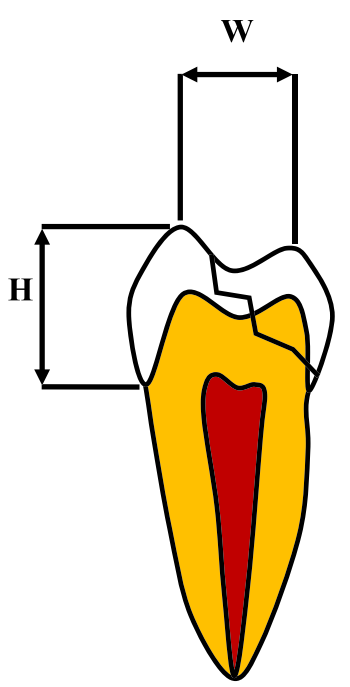

(a)

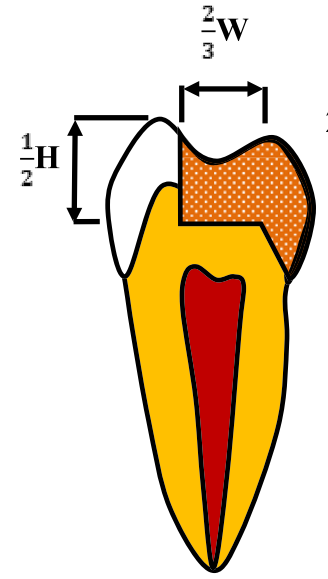

(b)

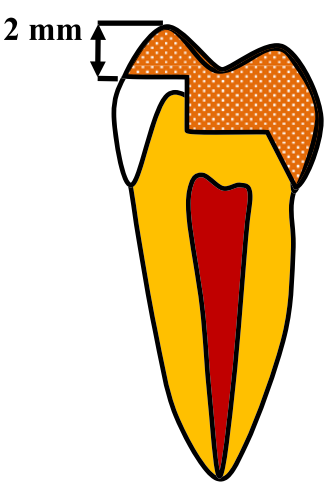

(c)

Figure 1 Cavities definition. (a) Intact premolar with typical MODP (mesial-occlusal-distal- palatal); i.e., loss of a functional cusp with a 45-degree bevel surface at the cervical margin; (b) Maxillary premolar with palatal cusp fracture without buccal coverage preparation (WOC); (c) Maxillary premolar with palatal cusp fracture with buccal cusp reduced in $2 \mathrm{~mm}$ height (WC). 


\section{Fracture and fatigue tests}

Three samples from the WOC and WC groups were randomly selected and mounted vertically to the long tooth axis for fixation in a universal testing machine (E3000, Instron, Canton, MA, USA). The test system was designed to drive a static compression force onto the tooth with a 4-mm steel sphere contacting the buccal and lingual cusps for axial loading (Figure 2). The crosshead speed was set at $0.05 \mathrm{~mm} / \mathrm{s}$ until a fracture occurred. The fracture load value was recorded.

The fatigue test cyclic loads were carried out by applying $200 \mathrm{~N}$ and $600 \mathrm{~N}$ onto the tooth with a 4-mm steel sphere contacting the buccal and lingual cusps to simulate the occlusal forces, respectively [28,29]. The $\mathrm{R}$ value (Fmax/Fmin) was set at 10 . The test frequency was set at $4 \mathrm{~Hz}$ because the human mastication frequency was found to be $1 \mathrm{~Hz}$ to $4 \mathrm{~Hz}$ from the literature [30,31]. Three samples each from the WOC and WC groups were tested at each cyclic load (200 N and $600 \mathrm{~N})$. The number of cycles at each load was set at $10^{5}$ because this number simulated chewing and swallowing for one half year [32,33]. A preload of $5 \mathrm{~N}$ was applied first on the tooth to test the stability between steel sphere and tooth before performing the static/dynamic compressive test.

\section{AE analysis}

An AE signal wide band transducer (Broadband sensor S9225, Physical Acoustic Corporation (PAC) Princeton Junction, NJ, USA) was glued with resin (Triad Gel, Dentsply, York, PA, USA) to the resin block in which the sample was embedded for the static compressive and cyclic load tests (Figure 2). Signals detected by the transducer were passed through $40 \mathrm{~dB}$ gain preamplifiers with a band pass of $100 \mathrm{k} \sim 2 \mathrm{MHz}$ (Model 2/4/6, PAC) $[17,20,34]$. The AE signals were recorded during the load period. The load versus AE hit in the fracture test and number of cycles versus AE hits in the cyclic load test (every 5000

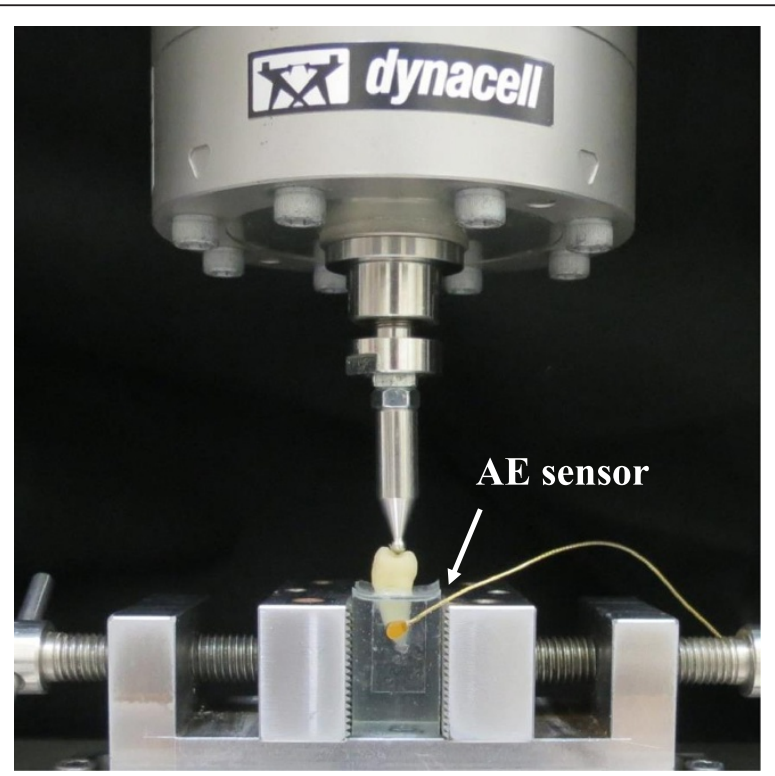

Figure 2 One of the tested restored tooth samples included a stainless steel sphere in contact with the buccal and lingual cusps for axial load and an AE signal wide band transducer glued with resin to the sample embedded in a resin block. 
of cycle load) for each sample were recorded to evaluate how the restored tooth failure process differed between static and fatigue tests. AE signal mean and standard deviations accumulated at each recorded time were computed. All data were statistically analyzed using the $\mathrm{t}$-test method $(\alpha=0.05)$.

\section{Results}

The $t$-test result in the fracture test displayed non-significant differences $(p>0.05)$ between the tested fracture loads for the mean WOC and WC restoration values (Table 1). However, significant differences $(\mathrm{p}<0.05)$ were found in the accumulated number of $\mathrm{AE}$ signals between these two restorations. The mean number of 15 for the WOC restoration was higher than 4 for the WC restoration. Generally, the tested loads and time required for the first $\mathrm{AE}$ activity for the WOC restoration in all samples were lower than that for the WC restoration. Test sample 2 in the WOC and WC restorations was selected on behalf of all test samples to show the typical load versus AE hit diagram in the fracture test. The result showed that tested loads $(130 \mathrm{~N})$ and time $(9 \mathrm{~s})$ required for the first AE activity for the WOC restoration was lower than that for the WC (1501 N and $67 \mathrm{~s})$ restoration (Figure 3). Different fracture modes in the restored teeth after fracture tests are shown in Figure 4.

No visible crack or damage was found in all samples after $10^{5}$ cycle loads with $200 \mathrm{~N}$ or $600 \mathrm{~N}$ according to the fatigue test results. The number of AE signals increased with the cycle load number and the accumulated number of $\mathrm{AE}$ signals under $600 \mathrm{~N}$ were higher than that under $200 \mathrm{~N}$. After $10^{5}$ cyclic loads non-significant differences $(\mathrm{p}>0.05)$ in the accumulated number of AE signals were found between the WOC $(42 \pm 8)$ and WC (44 \pm 14) restorations under the $200 \mathrm{~N}$ condition. Conversely, the corresponding mean value $187( \pm 13)$ for the WOC restoration was significantly higher than that of $85( \pm 9)$ for the WC restoration under the $600 \mathrm{~N}$ condition (Figure 5).

\section{Discussion}

Developed over two decades ago, the challenge of high performance ceramic and shaping it quickly and predictably to fit the defect in a damaged tooth has been the impetus behind advances in computer controlled machining in dentistry $[4,6,20]$. The CAD/CAM system has proven capable of restoring a large cavity chair side without the need for an impression or laboratory assistance [4-6]. However, the extensive cusp-replacing restoration fabricated without any reinforcement has doubtful structural stability and adhesive bond strength in long-term use. With special risk of cuspal fracture in an MODP restoration in premolars, Hannig et al. advocated that research should focus on in-vivo and in vitro studies evaluating ceramic restorations for reinforcement with and without cuspal (partial or complete) coverage [35]. In 2004 Fennis et al. reported that palatal cuspal

Table 1 Fracture load and accumulated number of AE signal in static fracture test

\begin{tabular}{ccccc}
\hline $\begin{array}{c}\text { Restoration } \\
\text { design }\end{array}$ & $\begin{array}{c}\text { Fracture load }(\mathbf{N}) \\
\text { (Mean } \pm \text { SD) }\end{array}$ & P value & $\begin{array}{c}\text { Accumulated number of AE signal (hit) } \\
\text { (Mean } \pm \text { SD) }\end{array}$ & P value \\
\hline WOC & $1427 \pm 309$ & 0.322 & $15 \pm 2$ & ${ }^{*} 0.018$ \\
WC & $1559 \pm 337$ & & $4 \pm 2$ & \\
\hline
\end{tabular}

${ }^{*}$ significant difference $(p<0.05)$. 


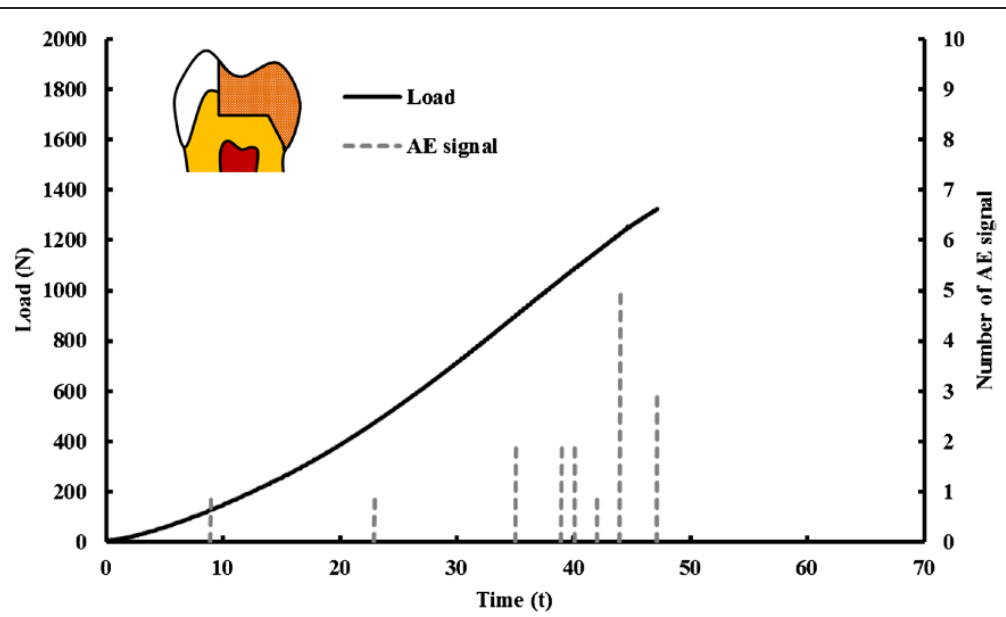

(a)

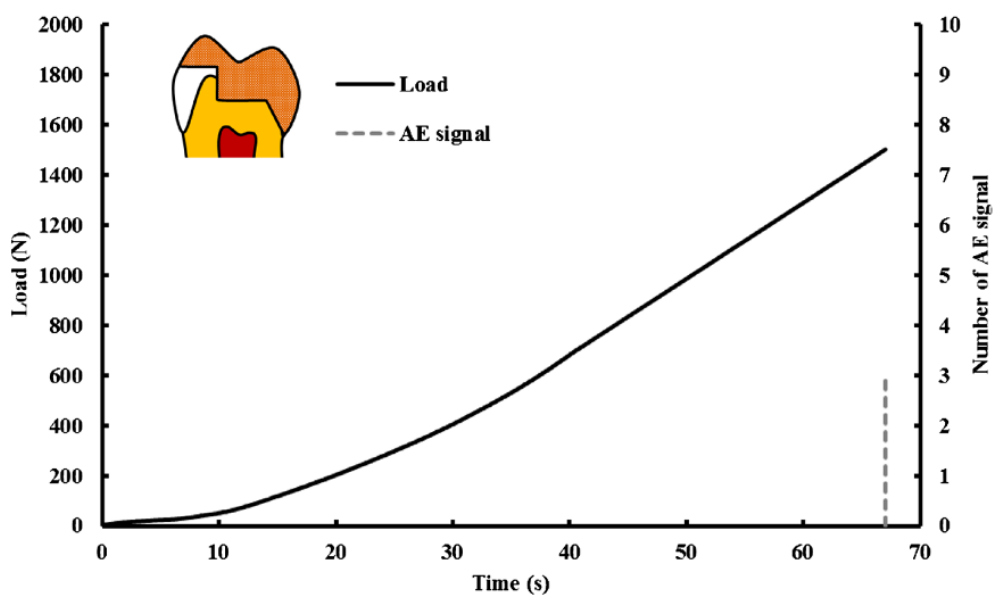

(b)

Figure 3 Typical example of AE signals in load/loading time graphs in fracture test. (a) WOC restoration and (b) WC restoration.

coverage increased the fatigue resistance of direct resin composite restorations. However, the direct resin composite cusp-replacement fracture mode might be unsuitable for restorations with CAD/CAM ceramic restorations [10]. Although our previous study indicated that cuspreplacement treatment was recommended to prevent palatal cusp fracture in extensively restored MODP premolar restorations. Reduction of the buccal cusp by at least $1.5 \mathrm{~mm}$ was seen to reduce stress. However, the clinical significance of the results from static FE analysis is occasionally questionable because a monotonic load does not accurately represent a clinical situation in which repetitive fatigue loading is characteristic [3].

Repeated load fatigue has been recognized as an important concept rather than a catastrophic event, inducing ceramic restoration failure. The AE technique has also been employed in dynamic fatigue testing in orthopaedic/dental materials. Roques et al. [18] used $\mathrm{AE}$ to assess bone cement failure using four point bending fatigue tests. Their results indicated that the $\mathrm{AE}$ technique can be used as a pre-clinical assessment tool for the integrity of cemented load bearing implants. Our previous study also used the AE technique to investigate micro-crack growth and damage in the ceramic/dentin adhesive interface 

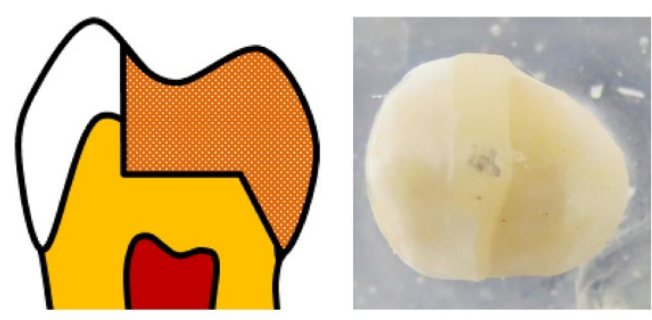

(a)
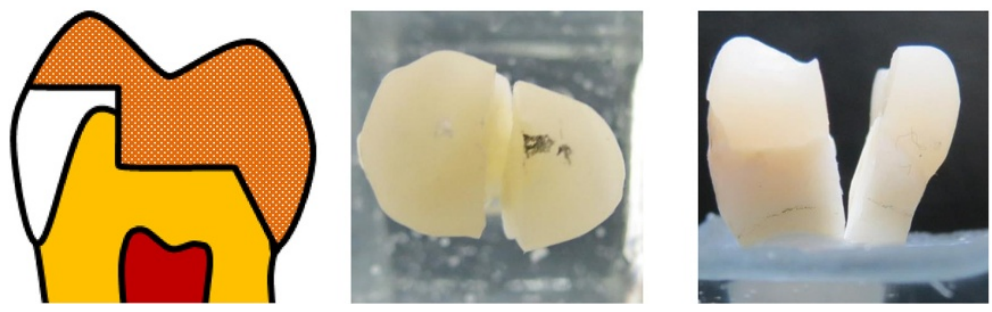

(b)

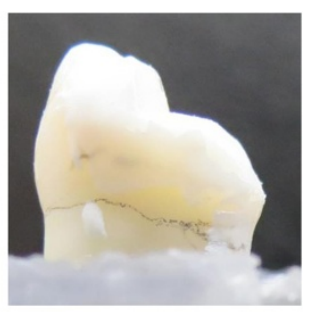

Figure 4 Fracture modes of the (a) WOC and (b) WC restored teeth after fracture tests.

under fatigue shear testing and found that the cumulative number of $\mathrm{AE}$ hits increased with a lower load level in cyclic load tests before fracture [27]. Therefore, this study attempted to combine the $\mathrm{AE}$ technique to monitor the failure process in CAD/CAM ceramic restored tooth with and without buccal cusp replacement under dynamic loads.

A small sample size with wide variability in the dimensions and mechanical properties of the teeth might cause the result to be judged with the "banal" argument. A study on a small sample is quite tempting and if the sample size is too small, the power of the results may be low to the point of unreliably. However, the importance of sample size calculation cannot be overemphasized because this study can be conducted for various objectives. In order to reduce the variability in the dimensions of the collected teeth, teeth with similar size and shape were selected using the root length and crown dimensions after measuring the buccolingual and mesiodistal widths at the cementenamel junction (CEJ) in millimeters, and allowing for a maximum deviation of $20 \%$ from the mean. However, the age of the patients with wide variability of the mechanical properties of the teeth was our limitation in this study.

Non-significant differences $(\mathrm{p}>0.05)$ between the tested fracture loads were found for the mean WOC and WC restoration values (Table 1). High standard deviations due to small size samples in the fracture test or unreasonable assumption (PDL non-linear material property, ill-condition element, loading and boundary conditions) in previous simulated FE models might be factors that caused the experimental result to not be consistent with previous FE studies. However, the AE signal was accompanied with final fracture, exhibiting the mechanism was prone to brittle fracture caused by catastrophic loading in the WC restored tooth (Figure 3(b)). The fracture type found in the WC restored tooth was from the central fossa to the deep root region and indicated that this catastrophic failure cannot be repaired again when fracture has occurred (Figure 4(b)). Conversely, the first AE signal relative to the received WOC restored tooth load was lower than the final fracture magnitude. The accumulated number of AE signals exceeded more 


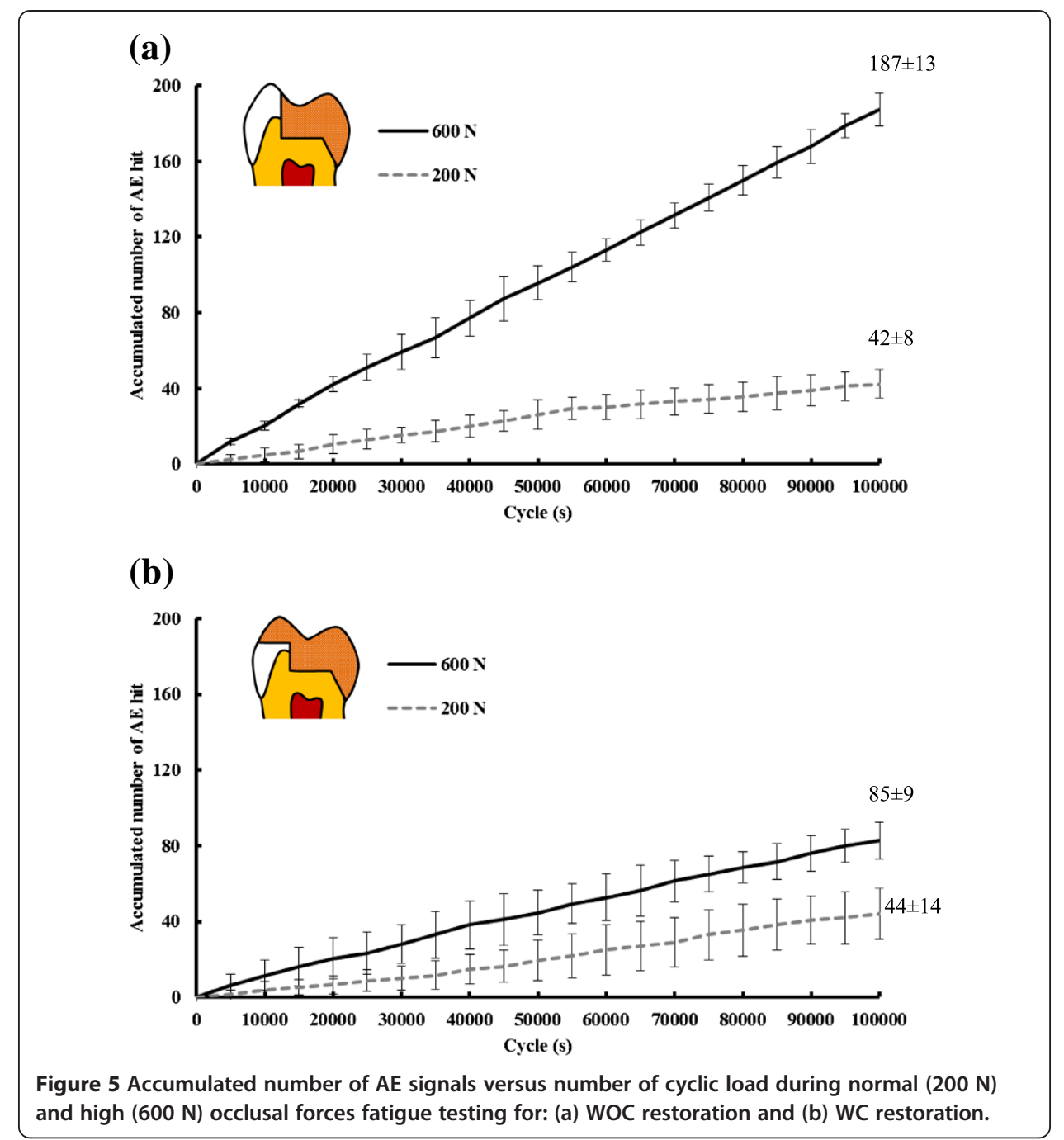

than 13 in causing the WOC restored tooth to fracture (Figure 3(b)). This phenomenon revealed that micro-cracks might be present in the tooth structure, cement layer or ceramic within the WOC restored tooth to propagate and eventually coalescence into larger cracks leading to failure [36]. The fracture in the WOC restored tooth was only found in the restored ceramic (Figure 4(a)).

The situation regarding the number of occlusal contacts that occur in vivo, Delong et al. addressed that chewing tooth contacts equal 240000 in one year [32]. Ruse et al. [37] pointed out that chewing and swallowing contacts equal 1800 per day. These numbers translate into $10^{5}$ in $2-5$ months. Owing to the constrained time available for collecting data, a $10^{5}$ cyclic load was used as the relative number to simulate clinical chewing.

The fracture test with fatigue test under $200 \mathrm{~N}$ indicated that significant differences in the accumulated number of AE signals cannot be found between WOC and WC restorations (Figure 5). This result pointed out that treatment in palatal cusp-replacing ceramic premolar restoration without (WOC) buccal cuspal coverage might withstand normal occlusal force for at least half a year. However, the accumulated number of AE signals for the WOC restoration was significantly higher than that for the WC restoration under the $600 \mathrm{~N}$ condition (Figure 5). High accumulated number of AE signals addressed the 
possibility of micro leakage in the restored tooth, in the tooth structure, cement layer or ceramic needed further consideration for long term use. The result also implied that people with para-function, heavy occlusal, bruxism may need treatment with buccal cuspal coverage to resist great occlusal force with high frequency. The aim of this study was to investigate the proper restorative technique for premolars with large functional cusp fractures. Due to the advancements in adhesive dentistry, onlay restoration has become an excellent conservation treatment option for these teeth. Preserving and protecting the remaining tooth structure should be the primary goal for all restorative systems. A fractured restoration can be remade, but a fractured tooth may become non-restorable. Therefore, emphases on protecting the remaining tooth structure with care in aggressive treatment (with coverage preparation) are needed.

This in vitro experimental study was designed to understand the relationship between the accumulated number of AE signals and fracture (load) resistance in preparation cavity designs for cusp-replacing restorations. Some clinical situations cannot be fully represented in this study and need to be assumed, such as load direction condition, cement thickness and the absence of periodontal ligaments (PDL) in the test samples. The resulting axial force crossing the central position (fracture or dynamic $200 \mathrm{~N} / 600 \mathrm{~N}$ ) force assumed in this study was not realistic and only approximated the complex balance between the masticatory forces and their reactions. However, the axial contact force transferred to the restored tooth may be resolved in tensile, shear and compressive forces on the adhesive interface, restorative ceramic and remaining tooth, except for near the load areas. Although there was an in-vitro test indicated for ceramic systems, there was no correlation between the cement thickness and micro-leakage either in the enamel or dentin [38]. Minimizing the gap between the prepared cavity and the restorative material should still be the goal for any restorative technique. Despite PDL not being simulated in our study, PDL either behaves as a rigid or non-rigid element, it is far away from the crown region and the stress distribution in the crown restoration may be assumed independent of the root region. This statement can be explained by the Saint-Venant principle [39].

\section{Conclusion}

Within the limitations of this in vitro study, the non-significant differences in results in the tested fracture loads and accumulated number of AE signals with normal occlusal force under fatigue testing implied that aggressive treatment (with buccal coverage preparation) requires more care in preserving and protecting the remaining tooth structure for palatal cusp-replacing ceramic premolar treatment. However, aggressive buccal coverage preparation for a palatal cusp-replacing ceramic premolar can be considered as the treatment type to gain stronger resistance from the restored tooth when it frequently receives high occlusal force.

Competing interests

The authors declare that they have no competing interests.

Authors' contributions

YHC and CLL conceived and designed the experiments; JJY [40] performed the experiments; YHC analyzed the data; YHC and CLL wrote the manuscript. All authors read and approved the final version of manuscript.

This study is one part of the Master Thesis of Jin-Jie Yu (2013) at the Department of Biomedical Engineering at National Yang-Ming University, Taiwan and supported in part by NSC project 100-2628-E-010-003-MY3 of the National Science Council, Taiwan. 


\section{Author details}

'Department of General Dentistry, Chang Gung Memorial Hospital, Ding-Hu Road, Kuei-Shan, Tao-Yuan 333, Taiwan.

${ }^{2}$ Department of Biomedical Engineering, National Yang-Ming University, No.155, Sec.2, Linong Street, Taipei 112 ,

Taiwan.

Received: 26 August 2014 Accepted: 19 November 2014

Published: 13 December 2014

\section{References}

1. Papa J, Cain C, Messer HH: Moisture content of vital vs endodontically treated teeth. Endod Dent Traumatol 1994, 10:91-93.

2. Sedgley $\mathrm{CM}$, Messer $\mathrm{HH}$ : Are endodontically treated teeth more brittle? J Endod 1992, 18:332-335.

3. Chang YH, Lin WH, Kuo WC, Chang CY, Lin CL: Mechanical interactions of cuspal-coverage designs and cement thickness in a cusp-replacing ceramic premolar restoration: a finite element study. Med Biol Eng Comput 2009, 47(4):367-374.

4. Al-Hiyasat AS, Saunders WP, Sharkey SW, Smith GM, Gilmour WH: Investigation of human enamel wear against four dental ceramics and gold. J Dent 1998, 26:487-495.

5. Chen HY, Hickel R, Setcos JC, Kunzelmann KH: Effects of surface finish and fatigue testing on the fracture strength of CAD-CAM and pressed-ceramic crowns. J Prosthet Dent 1999, 82:468-475.

6. Martin N, Jedynakiewicz NM: Clinical performance of CEREC ceramic inlays: a systematic review. Dent Mater 1999, 15:54-61.

7. Denissen H, Dozic A, van der Zel J, van Waas M: Marginal fit and short-term clinical performance of porcelainveneered CICERO, CEREC, and Procera onlays. J Prosthet Dent 2000, 84:506-513.

8. Martin N, Jedynakiewicz NM: Interface dimensions of CEREC-2 MOD inlays. Dent Mater 2000, 6:68-74

9. Lin CL, Chang YH, Liu PR: Multi-factorial analysis of a cusp-replacing adhesive premolar restoration: a finite element study. J Dent 2008, 36(3):194-203.

10. Fennis WMM, Kuijs RH, Kreulen CM, Verdonschot N, Creugers NHJ: Fatigue resistance of teeth restored with cuspal-coverage composite restorations. Int J Prosthodont 2004, 17:313-317.

11. Modelli J, Steagall L, Ishikiriama A, de Lima Navarro MF, Soares FB: Fracture strength of human teeth with cavity preparations. J Prosthet Dent 1980, 43:419-422

12. Lin $\mathrm{CL}$, Chang $\mathrm{CH}$, Ko CC: Multifactorial analysis of an MOD restored human premolar using auto-mesh finite element approach. J Oral Rehabil 2001, 28:576-585.

13. Fennis WMM, Kuijs RH, Kreulen CM, Roeters FJM, Creuger NHJ, Burgersdijk RCW: A survey of cusp fractures in a population of general dental practices. Int J Prosthodont 2002, 15:559-563.

14. Bader JD, Martin JA, Shugars DA: Incidence rates for complete cusp fracture. Community Dent Oral Epidemiol 2001, 29(5):346-353.

15. Lin $\mathrm{CL}$, Chang $\mathrm{YH}$, Chang WJ, Cheng MH: Evaluation of a reinforced slot design for CEREC system to restore extensively compromised premolars. J Dent 2006, 34:221-229.

16. Kuijs RH, Fennis WMM, Kreulen CM, Roeters FJM, Burgersdijk RCW: Fracture strength of cusp replacing resin composite restorations. Am J Dent 2003, 16:13-16.

17. Ereifej N, Silikas N, Watts DC: Initial versus final fracture of metal-free crowns, analyzed via acoustic emission. Dent Mater 2008, 24(9):1289-1295.

18. Roques A, Browne M, Thompson J, Rowland C, Taylor A: Investigation of fatigue crack growth in acrylic bone cement using the acoustic emission technique. Biomaterials 2004, 25(5):769-778.

19. Berkovits A, Fang D: Study of fatigue crack characteristics by acoustic emissions. Eng Frac Mech 1995, 51(3):401-416.

20. Lin CL, Chang YH, Pai CA: Evaluation of failure risks in ceramic restorations for endodontically treated premolar with MOD preparation. Dent Mater 2011, 27(5):431-438.

21. Alander $P$, Lassila LV, Tezvergil A, Vallittu PK: Acoustic emission analysis of fiber-reinforced composite in flexural testing. Dent Mater 2004, 20(4):305-312.

22. Duray SJ, Menis DL, Gilbert JL, Greener EH: Laser-induced acoustic emission in particle filled dental composites. J Dent Res 1995, 74:184.

23. Fennis WM, Tezvergil A, Kuijs RH, Lassila LV, Kreulen CM, Creugers NH: In vitro fracture resistance of fiber reinforced cusp-replacing composite restorations. Dent Mater 2005, 21(6):565-572.

24. Kim KH, Okuno O: Microfracture behaviour of composite resins containing irregular-shaped fillers. J Oral Rehabil 2002, 29(12):115311-115319

25. Vallittu PK: Use of woven glass fibres to reinforce a composite veneer: a fracture resistance and acoustic emission study. J Oral Rehabil 2002, 29(5):423-429.

26. Asaoka K: Effect of transient stress on acoustic emission behaviour during firing of dental porcelain. J Mater Sci 1992, 27:3118-3122

27. Lin $\mathrm{CL}$, Kuo WC, Yu JJ, Huang SF: Examination of ceramic restorative material interfacial debonding using acoustic emission and optical coherence tomography. Dent Mater 2013, 29(4):382-388.

28. Shiau YY, Wang JS: The effects of dental condition on hand strength and maximum bite force. Cranio 1993, $11: 48-54$.

29. Widmalm SE, Ericsson SG: Maximal bite force with centric and eccentric load. J Oral Rehabil 1982, 9:445-450.

30. DeLong R: Intra-oral restorative materials wear: rethinking the current approaches: how to measure wear. Dent Mater 2006, 22(8):702-711.

31. Ehrenberg DS, Weiner $\mathrm{S}$ : Changes in marginal gap size of provisional resin crowns after occlusal loading and thermal cycling. J Prosthet Dent 2000, 84(2):139-148.

32. DeLong R, Sakaguchi RL, Douglas WH, Pintado MR: The wear of dental amalgam in an artificial mouth: a clinical correlation. Dent Mater 1985, 1:238-242. 
33. Sakaguchi RL, Douglas WH, DeLong R, Pintado MR: The wear of a posterior dental composite in an artificial mouth: a clinical correlation. Dent Mater 1986, 2:235-240.

34. Li H, Li J, Yun X, Liu X, Fok AS: Non-destructive examination of interfacial debonding using acoustic emission. Dent Mater 2011, 27(10):964-971.

35. Hannig C, Westphal C, Becker K, Attin T: Fracture resistance of endodontically treated maxillary premolars restored with CAD/CAM ceramic inlays. J Prosthet Dent 2005, 94:342-349.

36. Erickson RL, De Gee AJ, Feilzer AJ: Fatigue testing of enamel bonds with self-etch and total-etch adhesive systems. Dent Mater 2006, 22(11):981-987.

37. Wiskott A, Nicholls J, Belser U: Fatigue resistance of soldered joints: a methodological study. Dent Mater 1994, 10:215-220.

38. Romão W Jr, Miranda WG Jr, Cesar PF, Braga RR: Correlation between microleakage and cement thickness in three Class II inlay ceramic systems. Oper Dent 2004, 29(2):212-218.

39. Hibbeler RC: Mechanics of materials. 7th edition. New Jersey: Prentice Hall Co, Inc; 2007:125-127.

40. Yu JJ: Monitoring dental adhesive layer failure and clinical application under cycling load. Master Thesis, National Yang-Ming University, 2013.

doi:10.1186/1475-925X-13-165

Cite this article as: Chang et al:: Examination of ceramic restoration adhesive coverage in cusp-replacement premolar using acoustic emission under fatigue testing. BioMedical Engineering OnLine 2014 13:165.

\section{Submit your next manuscript to BioMed Central and take full advantage of:}

- Convenient online submission

- Thorough peer review

- No space constraints or color figure charges

- Immediate publication on acceptance

- Inclusion in PubMed, CAS, Scopus and Google Scholar

- Research which is freely available for redistribution

Submit your manuscript at www.biomedcentral.com/submit 